\title{
Fashion and Brand Awareness: An Evidence-Based Approach to the Analysis of Distinctive Elements in Communication
}

\author{
Giovanni Maria Conti, Alessandra Mazzola, Martina Motta, Margherita Pillan \\ Dipartimento del Design, Politecnico di Milano, Milan, Italy \\ Email: giovanni.conti@polimi.it
}

How to cite this paper: Conti, G.M., Mazzola, A., Motta, M. and Pillan, M. (2020) Fashion and Brand Awareness: An Evidence-Based Approach to the Analysis of Distinctive Elements in Communication. Journal of Textile Science and Technology, 6, 177-189.

https://doi.org/10.4236/jtst.2020.64015

Received: May 27, 2020

Accepted: November 1, 2020

Published: November 4, 2020

Copyright $\odot 2020$ by author(s) and Scientific Research Publishing Inc. This work is licensed under the Creative Commons Attribution-NonCommercial International License (CC BY-NC 4.0). http://creativecommons.org/licenses/by-nc/4.0/

\begin{abstract}
Brand identity is a key topic in fashion design and communication. It relies on several tangible and intangible elements, such as recognisability of trademarks and styles, of materials and processing details, on storytelling, values, testimonials, company history and so on. The evolution of communication strategies in the digital era, and of globalised markets, demands rational, evidence-based management of the public image of brands. This article offers a theoretical discussion of the structural elements which play a part in establishing the public identity of fashion brands in the era of digital communication, and an innovative approach to the evidence-based investigation of the identity of a number of fashion brands as perceived by customers. The approach proposed here is based on a mix of interviews exploring subjective brand awareness, and objective monitoring of visual attention through eye-tracking. The article also summarises findings obtained by applying this approach to several subjects exposed to communication artefacts produced by fashion brands in order to obtain some information of general interest regarding the factors that influence customers' mental models.
\end{abstract}

\section{Keywords}

Fashion, Brand Design, Eye Tracking, Brand Identity, Communication, Experience

\section{Premise}

Our modern world is marked by ever accelerating of communication and a proliferation of channels and artefacts, all of which produce new challenges and opportunities in the communication of brands and products. Such changes are enabled by digital technologies, in which multiple virtual environments can be 
created in which information and ideas spread, and opinions, tastes and preferences take shape.

The contemporary tendency to intertwine the industrial world with those of design and communication has led to a multiplication of the elements involved in interactions between brands and customers in a variety of information flows and reciprocal influences: from the personalisation of products to co-design, from the reinforcement of brand loyalty through forms of product/service to the active involvement of customers in more or less spontaneous forms of advocacy [1] (Kotler, 2016), from storytelling in connection with production processes and company history to the sharing of identity and values [2] (Newberry, 2013).

The research we report in this paper focuses on the theme of brand identity as perceived by customers and by the public; our approach specifically considers brand identity as the composite, complex product of several heterogeneous factors which converge to determine the brand's distinctive elements and how the brand is perceived and recognised.

The long-term aim of our research is to identify approaches to investigating, analysing and modelling the different factors that determine how the public perceives brand identity; the approaches to which we refer are based on objective investigation and are supported by measurable evidence. Our study is based on the conviction that today it is possible to develop approaches which objectively analyze the impact produced by the different actions undertaken by a fashion brand to communicate its values, its distinctive, essential elements, and the specific nature of its creativity.

Our investigation of the elements that make a brand unique and recognizable aims to make their communication more effective (and therefore more efficient), but also and above all to close the gap between the values, which companies wish to communicate to the public and the values perceived by customers. The goal is to gather suggestions and hints with regards to how to develop and reinforce elements of brand identity, analyze patterns of relationships between brands and customers, and explore new ways of engagement [3] [4].

The investigation reported in this paper was carried out with the collaboration of two different research groups at the same research institution as ours Politecnico di Milano.

The two groups, specialising respectively in fashion design and communication design collaborated jointly on this study, thus offering distinct yet complementary contributions related to their specific discipline.

The research involved a series of experiments conducted on panels of individuals who were placed in contact with communication artefacts produced by various brands in the fashion industry. The experiments included interviews as well as a number of investigations into perception based on eye tracking techniques in order to gauge levels of engagement and attention.

The results of these experiments point to the possibility of mapping and comparing the main elements that constitute brand identity for actual and potential 
customers.

Our approach aims to provide tools for studying trends, preferences, and references in a way that is complementary to approaches based on the analysis of digital data. We argue that qualitative analysis is particularly important if we wish to "understand" rather than quantify, and that detailed analysis of experience is capable of producing suggestions and ideas for creative innovation [5] (Lindstrom, 2016).

The article illustrates results mainly obtained in tests involving students attending the degree courses in Fashion Design and Communication Design at School of Design, Politecnico di Milano. These results reveal how the analysis enabled by instrumentation highlights the different semantic maps underlying brand identity as perceived by the young people whom we involved. Finally, the article summarises the results of the study and illustrates some of the many paths companies operating in today's fashion industry can take in order to characterise their brand image.

\section{Fashion and Brand Identity}

Fashion embodies and represents various, multi-faceted symbolic values which are recognisable in different socio-cultural fields. The social and individual values which are intrinsic to fashion are disseminated in the shapes, features, details, materials, functions of products and accessories. Brand identity is the final outcome of several different layers of thinking and design activities, ranging from the product to its staging, and passing through the creation and communication of possible worlds, lifestyles, and opportunities for personal expression.

Fashion "is a problem that is anything but frivolous, because it has its roots in religion, politics, and art. Fashion is a topic that affects the structures of custom and culture, society, taste" [6]. According to Roland Barthes, fashion is the privileged subject of sociological investigation, strongly differentiated by dress as a technological object, the ornament as an aesthetic object, and custom and culture. [7] (Barthes, 1970); thereafter, fashion today appears as a representation of a mass phenomenon which, through complex dynamics, tells us about the evolution of costume, ideas, and collective behaviour, being essentially constituted by intuition, creativity and taste.

The American Marketing Association has defined the brand as "a name, term, sign, symbol, or design, or a combination of them, intended to identify the goods and services of a seller or group of sellers and to differentiate them from those of competitors." This concept specifically emphasises the brand's semantic function, i.e. the basic function that allows a specific bidder to be associated with specific goods and services.

\section{Communication in Fashion}

The last few decades have seen a proliferation of communication tools, including 
transmedia, multiple-channel and cross-media communication, and storytelling [8] (Giovagnoli, 2013). The accessibility of immediate, ubiquitous online information from companies as well as from their customers and supporters has modified the processes through which fashion trends are born. However, it has also made them easier to analyse. Companies adopting a design approach that focuses on experience have rendered the processes of acquisition, interpretation and abandonment of trends even more rapid than in the past, while the global stage has multiplied and diversified social and individual interpretations and meanings of forms, signs and symbols [9] (Garrett, 2011). In this context, digital technologies provide the tools but also increase the need to develop the ability to listen to customers; companies should consider essential key to their success the ability to develop evidence-based research with a view to analysing the effectiveness of their actions to build and strengthen their brand identity.

Companies have multiple channels at their disposal to communicate products, styles, values: traditional print media, websites, social networks, blogs, online sales channels, and so on. These channels provide the means to create complex communication "events" capable of reaching different kinds of customers and multiplying the number of potential virtual showcases and paths that lead customers from the product to the brand and vice versa. Furthermore, these communication channels allow the brand identity spread across a larger number of product lines, thereby also creating alternative conversations with clusters of customers through different channels and thus responding to different needs and objectives [10] [11]. Companies offer a storytelling context to customers, not just through products but also (or mainly) through values and creative stimuli. At the same time, companies can harvest the stories shared by users and customers to enrich and develop the creative interpretation of products and styles [12].

Customers have a variety of stimuli at their disposal to hence develop their own personal angle on information about products and styles released through the brand's communication channels. On the whole, the final identity of a brand, as perceived by customers and the public, is influenced by tangible elements (such as products, materials, details, testimonials, communication artefacts, services, and so on) and intangible elements (such as values, stories, place of origin, reference to tradition, and so on), which can converge or diverge, thus creating its public image and how this evolves over time.

On the other hand, the intrinsic characteristics of the Internet and social networks mean that one company's online communication inevitably cuts across that of other companies, which may be similar or different in terms of size, primary market and target audience. In this context, an analysis of the possible misalignment between the intended communication and its reception by customers and public may help design-driven companies to develop a more rational approach to devising creative strategies [13].

Evidence-based investigations aim to provide an overview of the different 
ways customers and people interpret design and communication choices and a fuller understanding of their effectiveness.

In our research, we framed the relationship between a brand and its customers as a significant form of experience, and as a dynamic process that is constantly evolving over time and has to be continually nurtured and revived.

In addition, we considered the importance of understanding the brand's spread, i.e. identify clusters of customers based on different perception and meaning-making paths based on the same product and communication features. Our main goal was to identify the signs that differentiate one brand from others in customers' minds and to interpret their contribution as they influence the brand's image.

\section{Experiments and Tools for Analyzing Brand Identity}

Evidence-based analysis of how brand identity is perceived and interpreted is a tool that companies can use to gain greater awareness of the meanings that styles and communication produce, and the variety of subjective interpretations.

Brand awareness is a complex area of investigation in itself, and often highlights a significant misalignment between the references which companies put in place and deem important in terms of brand identity used and the elements, of products, processes, iconic symbols, communication and values, that are remembered by the public.

We designed our research method to investigate the factors that characterise brand identities in terms of how brands are perceived by their target, and to investigate the specific dynamics and possible tensions between the recognisable aspects of brand identity and markers of a brand's public image, including in relation to current trends.

Our approach integrates many different actions, from expert analysis by designers to interviews with representative samples of users and the acquisition of biometric data for a detailed examination of the visual and cognitive perception of communication artefacts. The combination of traditional research with biometric techniques and, in particular, with perceptual analysis based on visual monitoring (eye tracking) is not a new practice in design, [14] (Pernice, 2017), and even in the specific field of fashion. Authors such as Ware [15] [16] have investigated the mechanisms of human perception in great detail, while others, such as Duchowski [17] have proposed a framework for experiments based on eye tracking. Eminent researchers such as Kahneman have also used eye tracking investigation to explore mental processes [18] [19]. In the fashion domain, authors such as Wedel [20] have used eye movement monitoring techniques to investigate the ability of advertising messages to capture the attention of and be remembered by their audience and studied the links between motivation, interest and ocular attention in the choice of brand; similarly, Ju and Johnson [21] (Ju 2010) studied the eye movements of young women to understand how to segment the audience of fashion advertisements based on personal and in- 
dividual perceptual characteristics. More recently, Faria et al. have presented a review of the state of the art of results of the use of eye-tracking in the field of fashion [22] (Faria 2018), showing how combining instrumental measurements with other forms of investigation provides useful information for fashion practitioners.

To the best of our knowledge, having extensively surveyed the literature of the sector, our approach is original, given the complexity of the investigation.

\section{The Results of Expert Analysis}

We have carried out several experiments, the aim of which has been to refine our research methodology, and the results of which focus mainly on mid-to-high-end fashion brands, such as Gucci, Missoni, Max Mara, Cucinelli, Burberry, Fendi, Peserico, and others. For the brands that we analysed, we first conducted expert evaluations of advertising campaigns and information on various media, including printed catalogues, proprietary websites and social networks. We selected the brands for our experiments according to several criteria: history, international presence, recognisability of products and secondary lines, and similar or comparable target clients.

From the expert evaluation, the different strategies that brands use to mark their identity and guide the public in recognising brands and products clearly emerged.

Each company has its own communication strategy based on a particular mix of variables which we discussed in the first part of this article. These include: logos, variations and placement; testimonials as part of the history of the company (as in the case of Brunello Cucinelli, founder of the company of the same name); storytelling expressed in terms of reference contexts, the expression of values, of real or imaginary situations, and of suggestions, the recurrent use of recognisable elements in materials, colours, techniques, finishes, decorative patterns on fabrics, the relationship with customers, the involvement of customers in conceiving of new product interpretations; the promotion of original ways of understanding the brand; opportunities for product customisation; the diversified yet consistent use of the various communication channels, from traditional to digital and bidirectional media.

Each company expresses its personality and its values through a specific combination of the degrees of freedom of product design and communication. This personality may be strong and consistent, or it can be fragile, confused or blurred. What is more, there is no precise rule that defines the correlation between the specific mix of choices made by a brand and the significance that the brand communicates to its customers. Brands may therefore be very active in devising new products and communication interventions which however fail to transmit a clearly defined image.

\section{Eye-Tracking Experiments}

In the analysis of brands, we performed two different experiments based on 
eye-tracking measurements.

The purpose of the first experiment was to verify brand awareness based on intrinsic features of the products and on their "learnability", i.e. the ease with which the participants interviewed could learn and recall the distinctive signs that make a product part of a specific brand.

In the second experiment, we focused on the more complex and, we believe, more interesting task of analysing the complex dynamic processes between perception and cognition. In other words, we set out to investigate how the knowledge and mental image that different subjects have of a brand influence and are conditioned by new visual stimuli, and by newly proposed products and communication.

The subjects involved were divided into two groups, one for each experiment, and numbered about ten people of both sexes, all with a keen interest in fashion, many of whom are students attending the three-year degree course in Fashion Design at the Politecnico di Milano (Figure 1).

The first interviews collected related to the subjects' preferences, habits, and, more generally, the different ways in which they accessed information and made comparisons with regard to the fashion world. Subsequent interviews investigated their attitudes towards the brands involved in the experiment and what they remembered as being their distinctive features specifically connoting those brands (Figure 2).

We then proceeded to involve all of the subjects of the experiment, one at a time, and showed them the images related to some different brands (including Cucinelli Figure 3, Burberry Figure 4 and Figure 5, Ralph Lauren Figure 6 and Max Mara Figure 7 as well as other), taken from the brands' official websites,

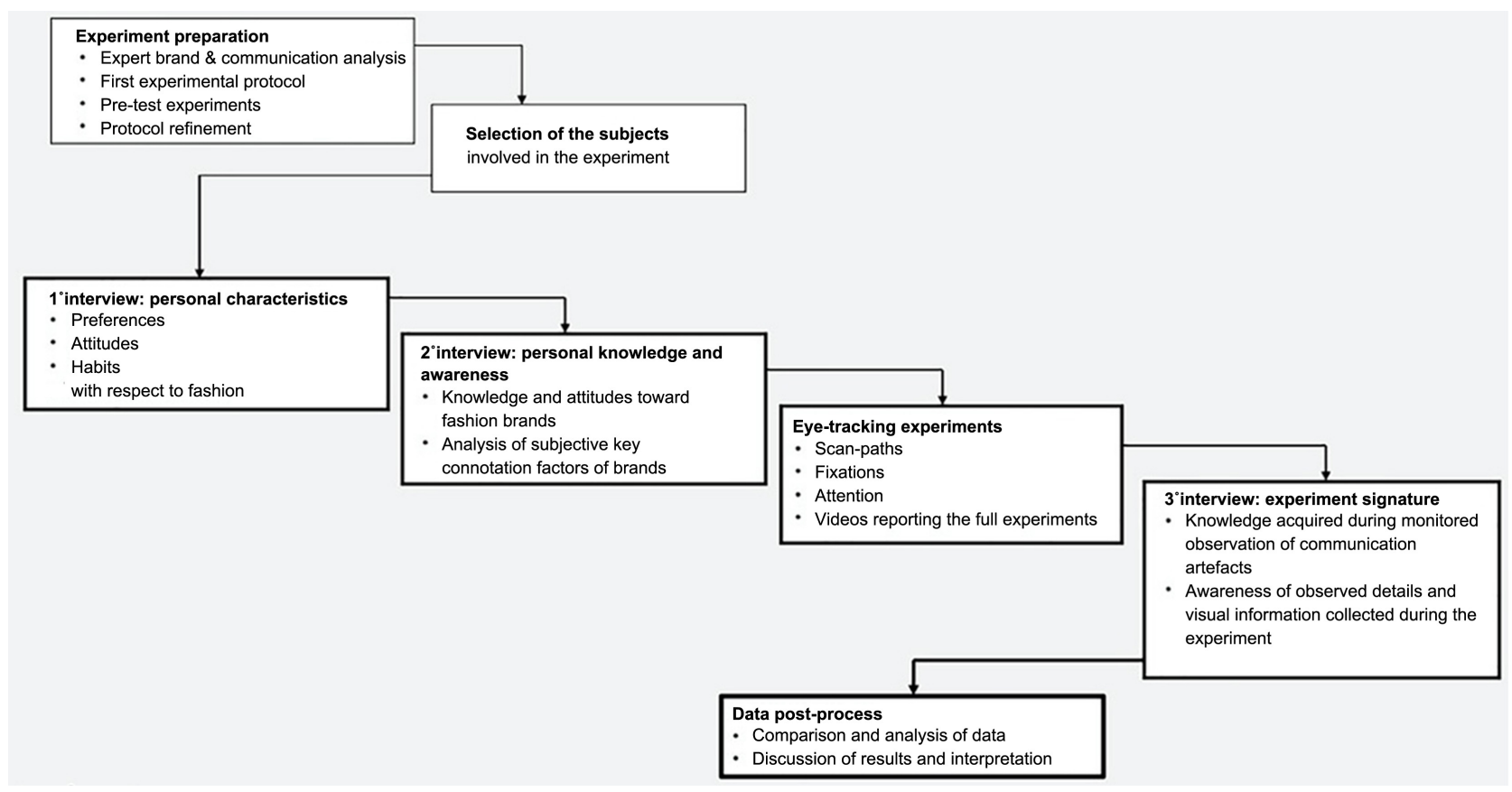

Figure 1. The main structure of eye-tracking-based experiments. 
Q4: Describe the brand Fendi in 4 Words

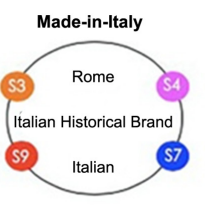

Q4: Describe the brand Max Mara in 4 Words
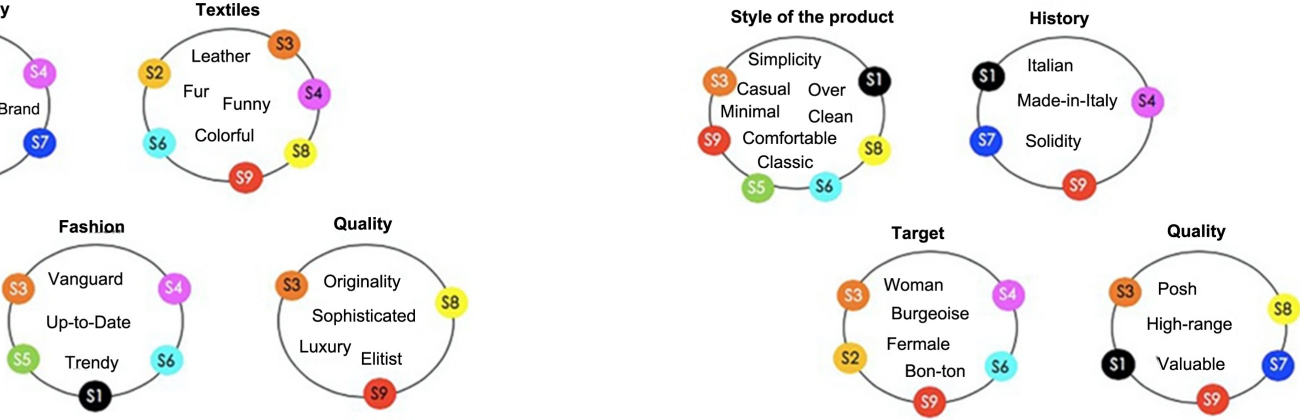

Figure 2. Keywords describing brands (Fendi, Max Mara). For each group of reported keywords, the " $\mathrm{S}$ " icons represent the individual subjects involved in the tests.

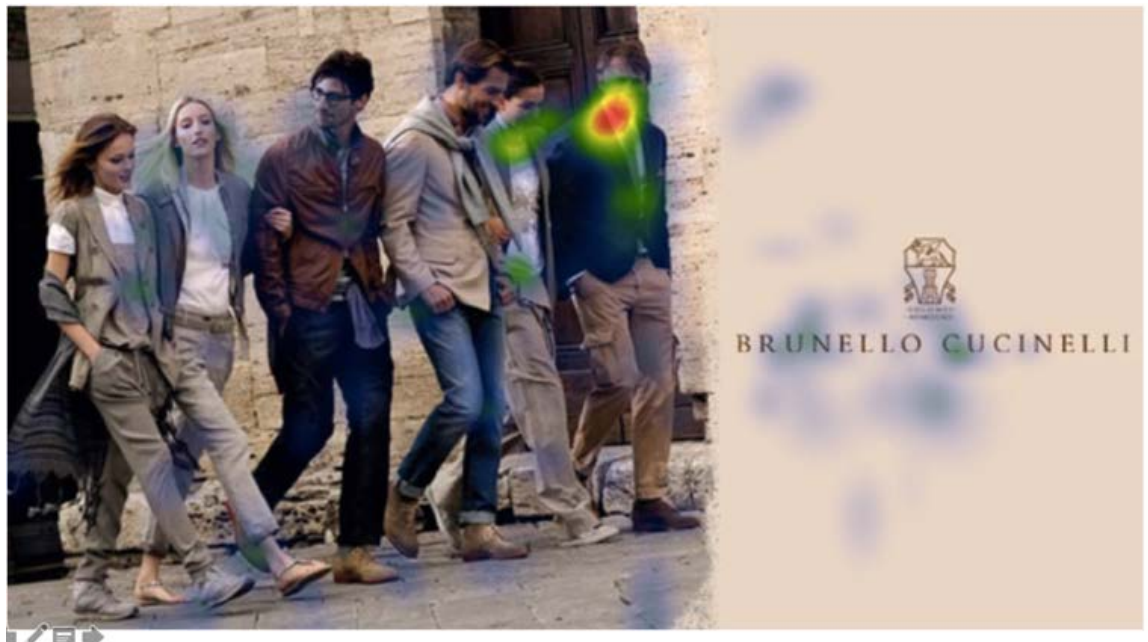

Figure 3. Heat map revealing the areas of maximum interest for a Cucinelli website.

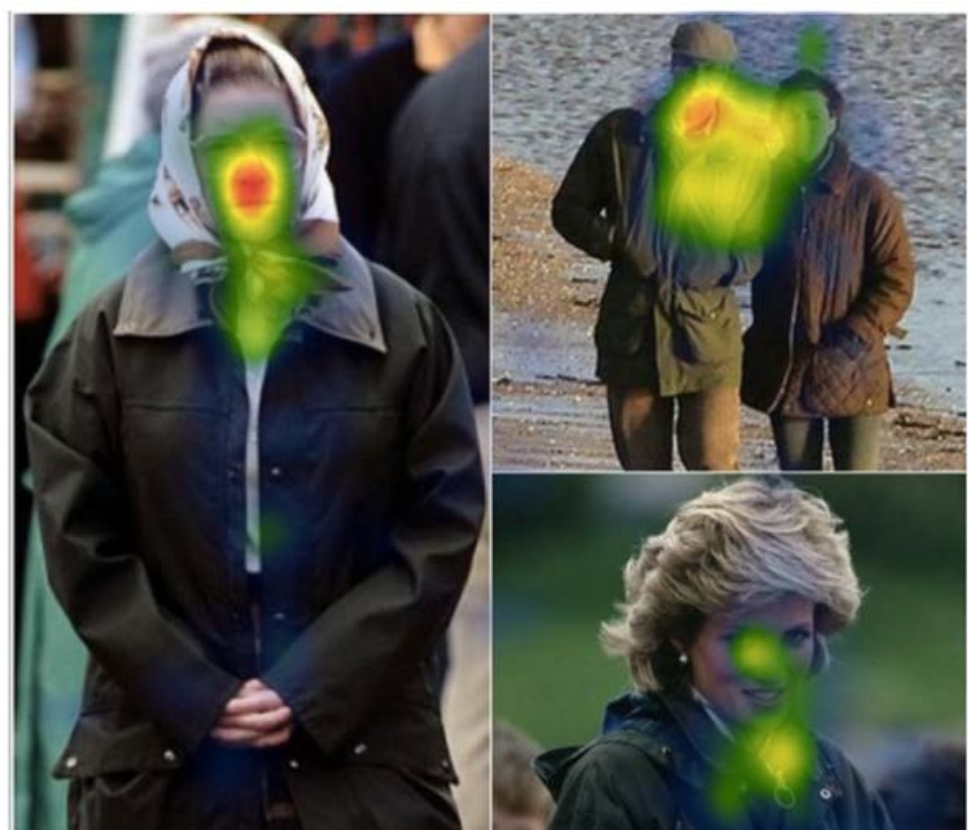

Figure 4. The heat map (maximum interest) for images from Barbour's. 

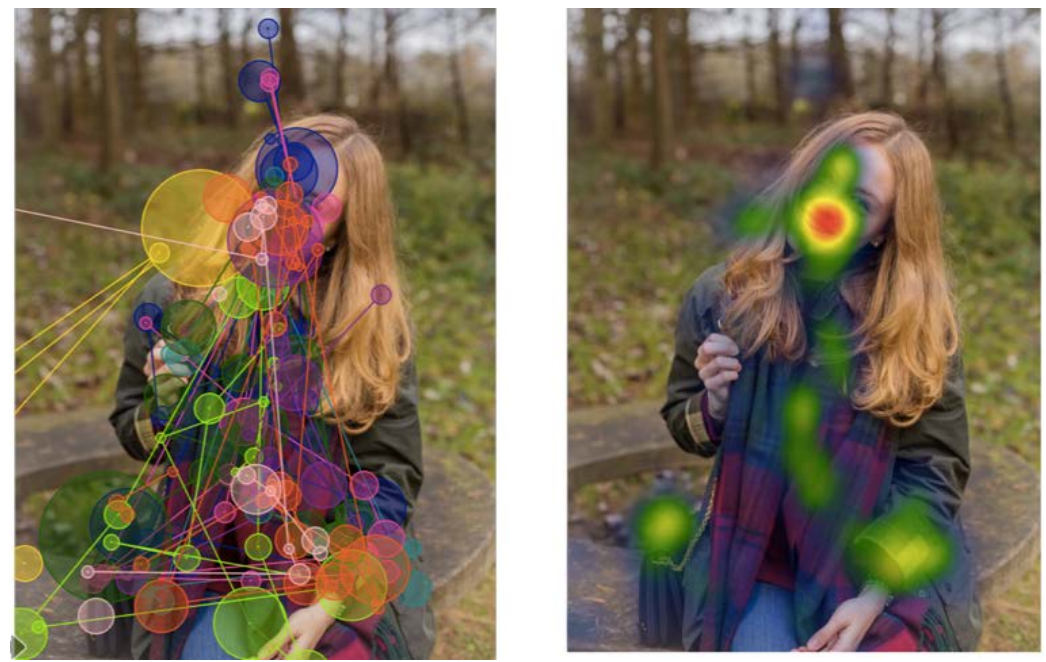

Figure 5. Eye-tracking measurements for Barbour. On the left: the sequence of gaze fixation). On the right: areas of interest for the all the subjects involved.
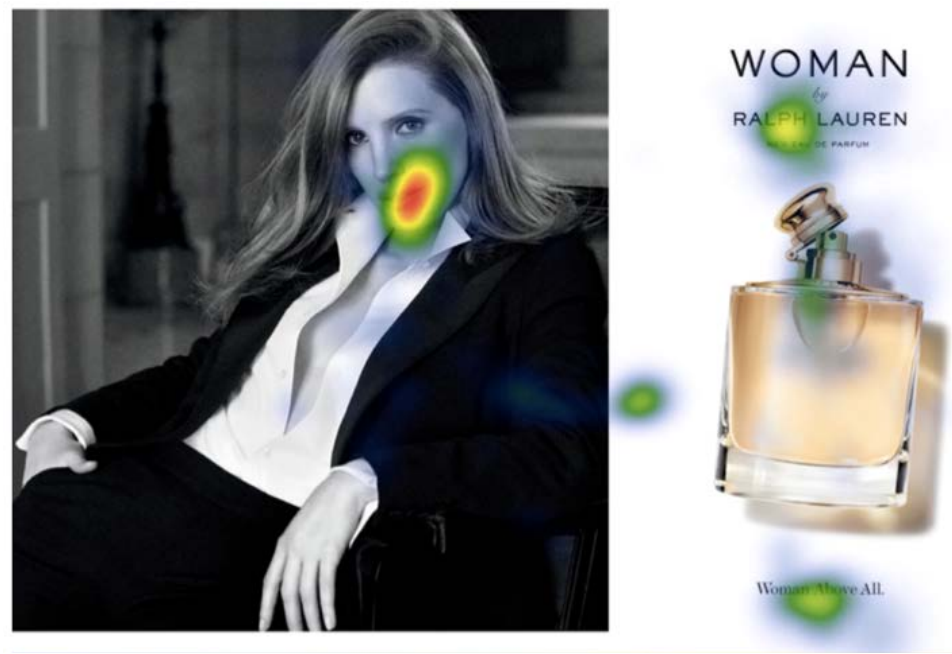

Figure 6. Heat maps and scan-paths for an advertisement by Ralph Lauren.

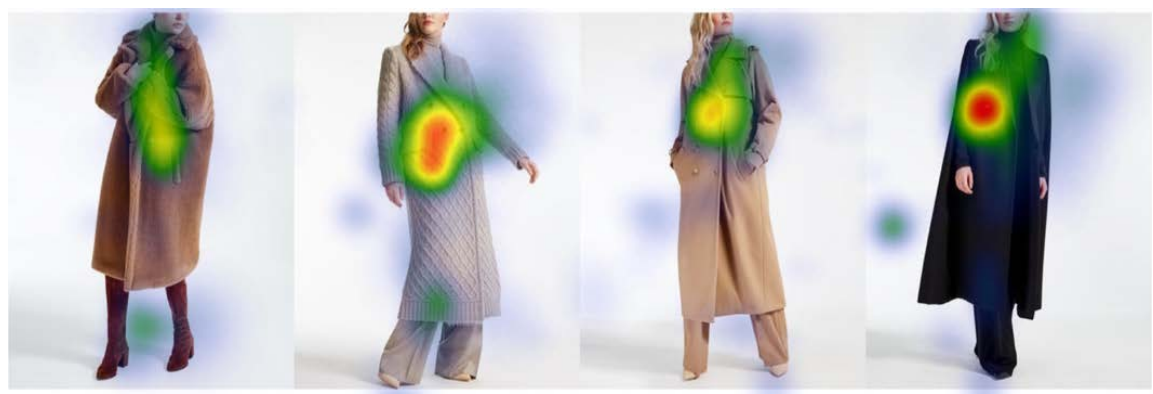

Figure 7. Comparative areas of attention for Max Mara.

catalogues, recent advertising campaigns, and proprietary spaces on social networks.

During this phase of the experiment, we collected data on the visual behaviour of all the subjects using eye-tracking instrumentation. Eye-tracking analysis al- 
lows the accurate recording of what people actually observe, the sequence of ocular fixations on the different details of an image, of the duration of those fixations and other potentially attention-related parameters.

Finally, we conducted interviews to understand how exposure to these visual artefacts impacted the opinions and evaluations of the subjects involved in the experiment. The results not only provided some indicators regarding the effectiveness of communication of the individual brands, but also some general considerations which we report below.

\section{General Results}

The first result that we consider significant regards the fact, which is well established in the fields of visual and human perception, that what we know and think strongly conditions what we see and how we interpret it.

To see is mainly to recognise; the interpretation of what we see always involves the use of memory and the comparison between the new stimuli and information stored in the mental frames that we have constructed over time. Images are made up of "anchors", recalling details we store in our mind and of main visual features combined with elements of subjective and social evaluation.

In our experiments, most of the subjects unconsciously looked for recognisable signs and their gaze lingered on them for longer than on the rest of the visual field. For instance, some subjects, during the third interview, recalled "woollen sweaters" when they were asked to tell what they had learned about a brand renowned for this kind of product, even when no sweaters were included in the images presented to them.

Following our findings, we argue that innovation is appreciated by customers when it is proposed in terms of style, and when it is related to the context and to the interpretation of a known product. However, innovation must be consistent with the values and principles that are attributed to the brand, or else it can be unsettling and viewed with suspicion.

From our experiments we conclude that the public is fascinated by brands that have a strong and clearly distinguishable personality, both when it is associated with a long and tradition-rich history and when it is linked to the power of seduction of a single person who represents the whole brand.

Mental models are very powerful: subjects who view, for example, a detail-laden image taken from the Cucinelli website, almost exclusively pick up on what is consistent with the idea that they have of the brand and its products.

In order to appeal, a brand must convey complexity and enduring values, but at the same time not trivial in its recognisable manifestations.

Many of the subjects that we interviewed said that they enjoyed the process of decoding messages that are variously communicated by brands in order to vary their identity and to express their values under continuous formal innovation. This finding is consistent with Ramachandran's theories [23] (Ramachandran, 2011), and, notably, with the phenomena of peak shift and perceptual problem solving, which are considered basic, biologically-based, elements of the aesthetic 
experience. Our experiments show that interest is stimulated by novelty, and that positive evaluation is also linked to continuity and consistency.

The second aspect on which we want to focus our attention is the power of visual communication compared to words. The brands we examined employ very different strategies to produce recognition and identity. For example, a brand such as Fendi proved to be difficult to describe in words but very clearly identifiable from the strength, energy, and spirit of its visual communication.

Fendi plays with its logo in a witty, innovative way, keeping it always in sight in a way that is sometimes playful without sacrificing "glamour".

The identity of brands such as Cucinelli, in contrast, is inextricably bound up with their history and founder, who is systematically recognised and observed in the images in which he or she appears, sometimes even upstaging the products themselves. Our experiments showed that the products themselves are generally not recognisable if separated from the context. Cucinelli's communication, however, is immediately recognisable or, for those who were not familiar with the brand before our experiment, is easily learned and identified, thanks to the contexts and interpretations of clothes, worn in a way that is never trivially faithful to a rigorous style.

While both approaches have their own characteristic appeal and are effective in making the brand recognisable, our comparison between the different strategies adopted by the brands leads us to believe that in the long term it is more worthwhile for brands to promote a story about their values and inspiring principles based on formal and visual innovation than to rely on storytelling and textual declarations of values, as the latter requires a more rigid framework which imposes constraints, introduces references that can be interpreted more subjectively, making innovation more difficult.

On the other hand, when the identity of a brand can easily be summarised in words, because it is tied up with the local traditions of its place of origin or when specific factors particularly lend themselves to storytelling, it is easy for the public to speak about the brand in question, thus raising awareness of it by word of mouth and advocating for it.

In this case, the brand lives more through narration than a tangible awareness of products, and it would be interesting to better investigate the experience of customers who wear the products to understand what role is played by non-recognisability of products in shaping preferences.

Our investigations have shown that the ability of a brand to express itself through different product lines, including secondary lines, is an indicator of vitality and expressive power. However, as already mentioned, these secondary lines must either be consistent with the primary image, or to be capable of developing their own internal consistency and justification.

Greater variety in the range of products offered by a company, such as furniture or perfumes, does not seem to have a positive effect on how the company is evaluated. Nevertheless, small (i.e. accessible) accessories that embody the main symbols and values of a brand are quite highly appreciated and can be 
effective in reinforcing the brand's profile, recognisability and identity as clues in the "game" of brand recognition.

Lastly, the appeal of testimonials remains strong and effective beyond the realm of a brand's target users or users of the type of product being promoted.

\section{Conclusions}

For most fashion brands, the issue of a recognisable identity has always been crucial, in order to obtain loyalty and enhance their glamour and attractiveness.

Our experiments show the potentials of the investigations on brand identity are based on experiments including the use of instrumental facilities as eye-tracking. Furthermore, our research produced insights of general interests that could inspire strategies for communication in fashion.

Evolution over time is one of the key elements that constitute a brand's identity: customers tend to see brands as "people" and a personality to them, and as a result, integrate into their mental frame concerning the brand any information that they can possibly obtain. Effective methodologies to investigate customer perception of brands appear as promising means to cope with rapid changes of trends and attitudes.

\section{Conflicts of Interest}

The authors declare no conflicts of interest regarding the publication of this paper.

\section{References}

[1] Kotler, P., Kartajaya, H. and Setiawan, I. (2016) Marketing 4.0: Moving from Traditional to Digital. John Wiley \& Sons, Hoboken.

[2] Newberry, P. and Farnham, K. (2013) Experience Design: A Framework for Integrating Brand, Experience, and Value. John Wiley \& Sons, Hoboken.

[3] Kalbach, J. (2016) Mapping Experiences. O’Reilly Media, Sebastopol.

[4] Vitale, A.S. and Pillan, M. (2016) Products as Communication Platforms. Investigating and Designing the Evolution of Retail Services in the Digital Era. The Proceedings of the 6th International Forum of Design as a Process, Systems \& Design-Beyond Processes and Thinking, Valencia, 22-24 June 2016, pages.

[5] Lindstrom, M. (2016) Small Data. St. Martin's Press, New York.

[6] Dorfles, G. (2000) La (nuova) moda della moda. Costa \& Nolan, Milano.

[7] Barthes, R. (1970) Il Sistema Moda. Einaudi, Torino.

[8] Giovagnoli, M. (2013) Transmedia. Storytelling e comunicazione. Apogeo, Milan.

[9] Garrett, J.J. (2011) The Elements of User Experience: User-Centered Design for the Web and Beyond. Second Edition, New Riders, Berkeley.

[10] Mosquera, A., Olarte Pascual, C. and Juaneda Ayensa, E. (2017) Understanding the Customer Experience in the Age of Omni-Channel Shopping. Icono 14, 15, 166-185. https://doi.org/10.7195/ri14.v15i2.1070

[11] Straker, K. and Wrigley, C. (2016) Emotionally Engaging Customers in the Digital Age: The Case Study of "Burberry Love". Journal of Fashion Marketing and Man- 
agement. An International Journal, 20, 276-299.

[12] Patton, J. (2014) User Story Mapping. O’Reilly Media, Sebastopol.

[13] Kalbach, J. (2016) Mapping Experiences. O’Reilly Media, Sebastopol.

[14] Pernice, K. and Nielsen, J. (2017) How to Conduct Eyetracking Studies. http://www.nngroup.com

[15] Ware, C. (2004) Information Visualization. Perception for Design. Morgan Kaufmann, San Francisco.

[16] Ware, C. (2008) Visual Thinking for Design. Morgan Kaufmann, San Francisco.

[17] Duchowski, A.T. (2009) Eye Tracking Methodology: Theory and Practice. Second Edition, Springer-Verlag, London.

[18] Kahneman, D., et al. (1969) Pupillary. Heart Rate, and Skin Resistance Changes during a Mental Task. Journal of Experimental Psychology, 79, 164-167. https://doi.org/10.1037/h0026952

[19] Kahneman, D. (2011) Thinking, Fast and Slow. Farrar, Straus and Giroux, New York.

[20] Wedel, M. and Pieters, R. (2000) Eye Fixations on Advertisements and Memory for Brands: A Model and Findings. Marketing Science, 19, 297-312. https://doi.org/10.1287/mksc.19.4.297.11794

[21] Ju, H.W. and Johnson, K.K.P. (2010) Fashion Advertisements and Young Women: Determining Visual Attention Using Eye Tracking. Clothing \& Textiles Research Journal, 28, 159-173. https://doi.org/10.1177/0887302X09359935

[22] Faria, A.P., Providencia, B. and Cuhna, J. (2018) Eye Tracking in Fashion: An Overview. In: Reverse Design: A Current Scientific Vision from the International Fashion and Design Congress, CRC Press, Boca Raton, 103.

[23] Ramachandran, V.S. (2011) The Tell-Tale Brain. A Neuroscientist's Quest for What Makes Us Human. W.W. Norton \& Company, New York. 